\title{
FEMINIZACIÓN Y ETNIFICACIÓN: LA REINA DE RAPA NUI DE PEDRO PRADO'1.
}

\author{
Sonia Montecino y Rolf Foerster ${ }^{2}$ \\ Universidad de Chile
}

\section{RESUMEN / ABSTRACT}

A través de la lectura de La Reina de Rapa Nui de Pedro Prado como un dispositivo colonial y de género, es posible conocer el rostro que adquiere el vínculo entre el Estado chileno y el pueblo rapanui, así como la construcción de un imaginario (feminización y construcción de isla oceánica) que oculta la historicidad conflictiva de esa relación, al mismo tiempo que la devela en su negación. Lo anterior se torna también visible cuando se ponen en relación los distintos contextos político-culturales de las reediciones de la novela y las imágenes de sus portadas.

Palabras Clave: Rapa Nui, Pedro Prado, dispositivo, colonialidad de género.

By reading Pedro Prado's novel The Queen of Rapa Nui as a colonial and gender device, a deeper understanding of the relationship between the Chilean State and Rapanui people emerges. One may also understand how the imaginary of feminization and oceanic island construction is built. Such imaginary hides the conflictive historicity of the relationship, while revealing it in its own denial. This also becomes visible when the political and cultural contexts of the several publications of the novel and their cover images are put in relation with each other.

KEY WORDS: Rapa Nui, Pedro Prado, Device, Gender colonialism.

$1 \quad$ Este artículo forma parte de la investigación Fondecyt $N^{0} 1140927$ (2014-2016). Agradecemos a Alejandra Araya, Larisa Deruyt, Adriana Valdés y Gloria Cortés sus sugerencias, sus préstamos de libros y su interés por dialogar en torno a este artículo, enriqueciéndolo.

2 Doctora en Antropología, profesora titular del Departamento de Antropología, Universidad de Chile. Santiago, Chile. E-mail: monteci@uchile.cl; Rolf Foertser, Doctor en Antropología, profesor asociado del Departamento de Antropología, Universidad de Chile. E-mail: rolf22@gmail.com 


\section{INTRODUCCIÓN}

Rapa Nui ocupa en el imaginario chileno un sitio ambigüo: por un lado, como isla oceánica, en el sentido de Deleuze ${ }^{3}$, puede comprenderse dentro de las "islas originarias" que aparecen conformadas por corales o que emergen de erupciones submarinas, a diferencia de las accidentales que se desprenden de un continente. Si bien ambas muestran la oposición océano/tierra, las primeras hacen que no olvidemos que la tierra está bajo el mar, pugnando por reventar. Las islas remiten a lo separado y en la imaginación, al sujeto solo en una isla recreando el mundo. Por el otro, aparece como isla antropógena (en términos de Sloterdijk 2009) que al ser construida humanamente y gracias a su aislamiento, la relación que se establece con ella se nutre de fantasía, de extrañeza y de dominio ${ }^{4}$. Tal vez la definición de "isla esporádica" es decir que se encuentra en el Chile insular, formando parte de un conjunto de pequeñas islas dispersas, entre las cuales además de Rapa Nui está Juan Fernández y Salas y Gómez, alegorice ese sentido de fortuito, ocasional, eventual, que se aloja en la compleja mascarada con que nos hemos relacionado con ella.

Nos proponemos dar cuenta de ese vínculo problemático a partir de la primera novela que se escribió en Chile sobre la isla: La reina de Rapa Nui de Pedro Prado, publicada en 1914 y que tuvo cinco reediciones a lo largo del siglo XX. Los contenidos de la novela, que han atravesado por décadas la mente de los(as) lectores(as) chilenos(as), nos dan pistas de cómo sobrevive un conjunto de representaciones de los “otros” isleños, y asimismo cómo sus ediciones se producen en contextos político-culturales que marcan conflictos o hitos de esa relación incierta entre Chile y Rapa Nui. La novela en tanto relato y en cuanto materialización libresca jugará un papel relevante para descubrir los entreverados hilos de la trama que se ha tejido entre chilenos y rapanui. Cuando ponemos en conexión esos contextos y las reimpresiones

3 Ocupamos aquí la traducción de José Blanco Regueira en Gilles Deleuze “Causas y razones de las islas desiertas". Se trata de un texto manuscrito de los años 50 que nunca fue publicado, pero que aparece en la bibliografía esbozada de Deleuze en 1998 bajo el título de “Diferencia y repetición”.

4 Podemos hablar de cuatro seducciones en ese vínculo: la geopolítica, la erótica, la religiosa y la monumental, todas ellas se asientan en un juego recíproco entre rapanui y chilenos lo que plantearía una relación colonial distinta a la que ha habido con los otros pueblos originarios (cfr. Rolf Foerster 2010). 
surge la hipótesis de que esta novela funciona como dispositivo ${ }^{5}$ y gozne articulador de los imaginarios nacionales y de género que cruzan las relaciones coloniales del “continente” y su “isla oceánica”. La noción de dispositivo, en este caso, se ocupa en su función de estrategia de dominio inscrita en un juego de poder y que se vale de un conjunto heterogéneo de prácticas y discursos cuyos elementos conforman una red. El dispositivo nace frente a una urgencia y ante la necesidad de producir un efecto y para Agamben es “...cualquier cosa que tenga de algún modo la capacidad de capturar, orientar, determinar, interceptar, modelar, controlar y asegurar los gestos, las conductas, las opiniones y los discursos de los seres vivientes. No solamente, por lo tanto, las prisiones, los manicomios, el panóptico, las escuelas, la confesión, las fábricas, las disciplinas, las medidas jurídicas, etc., cuya conexión con el poder es en cierto sentido evidente, sino también la lapicera, la escritura, la literatura, la filosofía, la agricultura, el cigarrillo, la navegación, las computadoras, los celulares y -por qué no- el lenguaje mismo, que es quizás el más antiguo de los dispositivos, en el que millares y millares de años un primate -probablemente sin darse cuenta de las consecuencias que se seguirían- tuvo la inconsciencia de dejarse capturar" $(2011: 257)^{6}$.

5 Utilizamos la relectura de Giorgio Agamben (2011) del concepto de Foucault.

6 Una revisión de algunas referencias críticas a la Reina de Rapa Nui avalan la interpretación de este libro como dispositivo de la relación conflictiva entre Chile y la isla. Marisol Galilea (2010) realiza un análisis iluminador al definir la novela como híbrida y al develar su trasfondo apocalíptico-catastrófico marcado por el contexto histórico pascuense. Por su lado, Raúl Silva Castro (1965) sostuvo que se trataba de una "construcción fantástica sobre un dato histórico” y centra el eje de su lectura en el amor entre el viajero y la reina, así como en el logro literario del "tratamiento de tan difícil tema”. Silva Castro da cuenta de dos reseñas realizadas en la época de su publicación: la de Omer Emeth (en 1914) que la elogia sosteniendo que el "protagonista esencial” es la isla y la baja calaña de Bornier y Adams (es decir, apunta al tema de la "isla oceánica" y al colonialismo); y la de Amanda Labarca (1915), que pone el acento en el exotismo de una novela que con "nacionalismo aborda lo pintoresco y extraño de los otros pueblos". El crítico Ernesto Montenegro (1952) la define como "fantasía romántica”, donde lo exótico se diluye en lo universal: “...salvo por la decoración natural y ciertas costumbres exóticas, el hombre es el mismo en todas partes" (99). Por su lado, Gabriela Mistral en 1932 en el diario La Nación, dice de Pedro Prado: “Alguna vez alcanzó hasta la Isla de Pascua, pasión de arqueólogos y de novelistas y que, geográficamente, es de la Oceanía y por una casualidad pintoresca, chilena. El viaje le sirve siempre a este hombre de ojos límpidos y atrapadores, como el del "cateador" coquimbano, y este viaje le dio uno de sus libros mejores en La Reina de Rapa Nui, relato de estilo forjado y de un exótico exento de las falsedades". Por último, Gotschlich (1996-1997) plantea que Pedro Prado desarticula las determinaciones epocales, rompiendo con los modelos normativos e ideológicos de la época. 
Antes de abordar el análisis, una breve digresión que problematiza la oposición continente/isla: en las representaciones que la literatura ha construido de Chile está precisamente la de autocomprenderse como "isla". Desde la mirada contemporánea de Roberto Bolaño en Los Detectives Salvajes (1998): “¿Ha oído hablar alguna vez de la teoría de Isla de Pascua? Esa teoría dice que Chile es la verdadera Isla de Pascua, ya sabe, al este limitamos con la cordillera de los Andes, al norte con el desierto de Atacama, al sur con la Antártica y al Oeste con el Océano Pacífico. Nacimos en Isla de Pascua y nuestros moais somos nosotros mismos, los chilenos que miramos perplejos hacia los cuatro puntos cardinales" $(395)^{7}$, hasta el propio Pedro Prado (1962) al inicio de su novela: "Se ha dicho que Chile es una isla, y yo creo que hay pocas islas tan islas como nuestro territorio. En realidad, sólo poseemos una extensa playa y si la contemplamos a la distancia azul y empenachada de nieve, nos parece una ola gigante floreciendo su espuma; y si trepamos por ella vemos, en los días claros, un océano inmenso" (29). Gabriela Mistral y Pablo Neruda, entre otros escritores, han elaborado y reelaborado esta visión insular que se ha adosado a la psiquis chilena y que podríamos comprender desde la idea de Sloterdijk (2009) de la isla antrópogena: "Junto a las configuraciones de islas nombradas por Deleuze, por erosión marítima y por emergencia terrestre del mar, aquí entra en consideración una tercera dinámica: el insulamiento por inclusión de grupos o por autorreclusión creadora de distancia” (275).

De este modo, la oposición geopolítica Chile Continental/isla esporádica de la nomenclatura oficial, se tensiona desde la cartografía mental chilena que ha trazado una concepción insular a su propio habitar, y así parece también querer decirnos La reina de Rapa Nui. La trama, narrada en 13 acápites, construye una "ficción histórica" aparentemente simple y envuelta en romanticismo. En el prólogo -que forma parte de la propia ficción- un hablante encuentra en los papeles de un conocido que ha muerto un manuscrito:

Pude ver que estaba incompleto y lleno de borraduras y tachas. Con gran cuidado lo he rehecho. El título, La Reina de Rapa-Nui es de mi invención. Las escenas que relata me parece fluctúan entre los años 1870 y 1874 , poco más o menos (25).

\footnotetext{
Nótese el parecido de esta imagen con la de Pablo Neruda en el Canto General en el poema VI "Los Constructores de estatuas": "No es así, las estatuas son lo que fuimos, somos/nosotros, nuestra frente que miraba las olas,/nuestra materia a veces interrumpida, a veces/ continuada en la piedra semejante a nosotros”.
} 
El texto se nos presenta como una reescritura (o una escritura a dos manos) del viaje de un joven periodista de Valparaíso a Rapa Nui:

¡La isla de Pascua, Rapa Nui! Cuando estudié geografía, mi ramo predilecto, me llenaba de orgullo el párrafo aquel que dice "Chile posee en la Oceanía la Isla de Pascua, la única colonia que puede ostentar la América del Sur” ¡La única colonia era nuestra! Encontré natural que se nos comparara a los ingleses. No se trataba de una gran extensión, pero en cambio era una tierra misteriosa (32).

El protagonista -sin nombre- emprende la travesía con el objeto de contar a su regreso el significado de "esa isla fantástica" y conoce en el barco al francés Dutrou Bornier y a su socio, el danés Adams, capitalistas y colonos que administraban la explotación ganadera instalada en la isla. El relato del viaje es breve, como queriendo acortar la distancia entre la isla-Chile y la isla Rapa Nui, sin embargo el narrador tiene completa noción, al arribar, de encontrase "muy lejos" (¿en una isla oceánica?) en medio del Pacífico y entre "salvajes", viviendo un "sueño estrambótico".

El núcleo de la historia es su encuentro con Coemata Etú, una bella nativa que gobernaba la isla y que, como es obvio, lo seduce. A través de las conversaciones con la reina y algunos indígenas, y en contrapunto con las visiones de los colonos, va conociendo los conflictos del lugar: por un lado, la lucha entre quienes acataron las reglas impuestas por los misioneros católicos y los que rompieron con ellas, liderados por Coemata Etú, quien al tener como amante a Dutrou Bornier lo hacía también rey (no podemos olvidar un dato relevante a la trama, el francés siguió viaje rumbo a Tahití y por ello la reina ostentaba la regencia de la isla). Por otro lado, una sombra se cierne sobre la ínsula: se anuncia y profetiza una sequía que aniquilará a los habitantes.

En medio de esos dos escenarios problemáticos, uno social y otro "natural", el joven periodista observa a una comunidad que se está destrozando, con suicidios de hombres sabios, enfermedades, lucha contra la sed, tras un telón narrativo que construye el pasado de guerras tribales cuyos vestigios se observan en medio de los ruinosos monumentos. Pero, junto a esa desolación y a las oscuras profecías, aparece una comunidad amorosa, que se reúne por las noches a tratar sus problemas, a bailar y cantar, a comer delicias, con una mirada sobre el mundo y las cosas que desafía a la propia, que persigue a través del rito domeñar la naturaleza y donde las mujeres vía la sensualidad o la reproducción juegan un papel fundamental. El nudo tenso del relato -todos 
morirán de sed-se resuelve con la muerte de la reina (por una fiebre) ${ }^{8}$ y con la llegada de la lluvia. El viajero entonces retorna a Valparaíso.

\section{LAS TRES TORSIONES DE LA NOVELA}

En esta síntesis apreciamos el hilo inocuo, la narración clásica de un occidental atraído por una nativa, sin embargo la apariencia "naïf” se desdibuja cuando hacemos una arqueología de la novela y su intertextualidad, ambos movimientos que develan otras operaciones simbólicas que, más allá del relato “aislado", muestran su alucinada propuesta ideológica y su función de dispositivo dentro de un contexto de colonialidad de género (Lugones 2008) ${ }^{9}$. El primer indicio relevante radica en que el autor, Pedro Prado nunca viajó a Rapa $\mathrm{Nui}^{10}$, y ello no sería un problema si su novela fuera solamente una "ficción", o una "novela juvenil del tipo fantástico" como dice Gallardo e Ivo $(2013)^{11}$, pues al rastrear en los viajeros y en la documentación oficial de fines del siglo XIX sobre Rapa Nui ${ }^{12}$, emergen otras señales, no ficcionales que como murmullos y memoria histórica se escuchan e infiltran en la novela.

8 Se trata de un tópico muy común en la novela romántica: la mujer que seduce y que finalmente muere, como Margarita Gautier.

$9 \quad$ Recordemos que para esta autora: “....necesariamente los indios y negros no podían ser hombres y mujeres, sino seres sin género (...) En tanto bestias, se los trató como totalmente accesibles sexualmente por el hombre y sexualmente peligrosos para la mujer" (130).

10 Gallardo e Ivo (2013) sostienen que: "Es una historia motivada por lecturas y en su ejecución revela en todo momento la condición libresca de su origen. La cultura y el paisaje de Isla de Pascua fueron en todo momento un componente artificial en la formación del poeta y eso queda claro en el texto de la novela (en el plano anecdótico, es simpático recordar que Pedro Prado nunca viajó a Rapa Nui y nunca afirmó haber viajado, pero con mucho sentido del humor dejó que más de alguno creyera que había vivido aventuras en la isla" (97). Gabriela Mistral (1932) como vimos fue una de las que creyó en la broma, pues Prado efectivamente fue un viajero "interno" que recorrió Chile hasta el extremo sur.

11 El autor tenía, sin duda, una imaginación prodigiosa, escribió junto a Antonio Castro, el libro de poesía Fragmentos, bajo la autoría del poeta afgano Karez-I-Roshan y editado en Montevideo. Se trató de una "broma” que perseguía desmontar los discursos de los críticos que leyeron en él poesía oriental pura. Sin duda, las lecturas de Tagore y otros poetas les permitió escribir una “impostación” impecable.

12 Indagación que hemos realizado en Documentos sobre Isla de Pascua (1864-1888) compilados por Rolf Foerster, Sonia Montecino y Cristian Moreno, Biblioteca Fundamentos de la Construcción de Chile, DIBAM, 2013. 
Se trata de, al menos, cuatro voces que sirven para modular-configurar la escena insular: por un lado, la correspondencia de los misioneros franceses del Sagrado Corazón (1863-1888), por el otro, y de manera rotunda, el escrito del Capitán de Corbeta Ignacio L. Gana (1870); los ecos del viaje de Pierre Loti ${ }^{13}$ de 1872 y el artículo de Rodulfo A. Philippi de $1873^{14}$. Las citas mudas de estos textos (los dos primeros escritos por testigos de primera mano) se despliegan a lo largo de la novela como un encaje de fragmentos que se hilvanan para -en sordina- evidenciar la "historicidad" del relato. Es desde estos trazos indiciales que podemos aproximarnos al segundo estrato de esta "ficción histórica" y leerla como dispositivo que devela la colonialidad chilena naturalizando la dominación a través de la representación literaria que ofrece La Reina de Rapa Nui, al mismo tiempo que la legitima, específicamente por medio del ensamblaje entre género y etnicidad ${ }^{15}$. Pedro Prado realizará un conjunto de torsiones -complejos malabares entre la fantasía y la historia-a las voces que le sirven para articular su mirada (sobre todo las del texto del Capitán Gana). La primera se relaciona con la representación de una jefatura política femenina; la segunda con la explicación de la violencia interna (vía la sexualidad) y la tercera con la interpretación relativista sobre el conflicto político cultural entre colonizadores y rapanui. Contrariamente a todos los documentos que Prado ocupa, la isla no es gobernada por arikis (jefes o reyes) hombres, sino por una mujer que ha llegado a serlo una vez que su padre, el Rey Tepito, ha muerto en un barco esclavista peruano, el heredero habría sido su hermano Gregorio, pero éste fallece porque los misioneros habrían roto el tabú de no tocar su cabello. Coemata Enú fue reina en medio de un contexto que favorecía la llegada de una mujer al poder. Narrado desde el punto de vista del colonizador Adams, emerge la figura fantasmática de Dutrou Bornier, como un "gabacho (que) le hacía el amor a la reina, y llegó a ser el verdadero príncipe consorte" (99), mientras el joven periodista cuenta:

13 En La Isla de Pascua, Diario de un Oficial del Estado Mayor de La Flore, 1872 en Documentos sobre Isla de Pascua (1864-1888), 2013.

14 “La Isla de Pascua y sus habitantes”, publicado por la Revista Anales de la Universidad de Chile. En Documentos sobre Isla de Pascua (1864-1888), 2013.

15 Esta cualidad de la novela de dispositivo que se arma en un guiño a la colonización chilena queda de manifiesto cuando el narrador sitúa los hechos del manuscrito entre 1879 y 1874 y su protagonista se enorgullecía de leer en el ramo de geografía que Chile ostentaba la única colonia de América del Sur, una tierra pequeña, pero misteriosa. Chile anexó a Rapa Nui en 1888, por ello esta incongruencia no hace sino delatar ese "deseo" ¿literario? de posesión. 
A mí me era agradable la compañía de la reina, porque olvidada de Bornier, había quedado gustando del trato con los extranjeros. Curiosa de las costumbres llamadas civilizadas, tenía sobre ellas juicios tan originales que me hacía admirar su inteligencia tranquila y libre (79).

La reina como toda la isla huele a flores, es pródiga en alimentar con ñames, está envuelta en un halo sensual, húmedo, marítimo; las oquedades de los volcanes, las cavernas, metaforizan la isla con tropos femeninos, así como los escenarios en los cuales el joven se relaciona con ella. La proximidad de Coemata Enú "perturba los sentidos" del hombre chileno, hasta que ambos, como "libélulas que juegan al amor" sienten el "ardoroso ruido de sus alas".

Desde una ecuación de género y etnicidad, la novela propone un quiebre aparente de las estructuras de poder masculino que prevalecían en Rapa Nui, pero sobre todo "desnuda" la colonialidad de género en la medida en que el cuerpo de la reina ha sido "ocupado" por un francés y en su ausencia por un chileno, que puede gozar de su “inteligencia tranquila y libre”. Por otro lado, al morir la reina, ya no hay más monarquía -pues ella no tiene descendencia-, la catástrofe de la sequía se desvanece y, si como leemos, el autor ha convertido metafóricamente a la isla en la categoría de lo femenino, se produce allí un vacío de poder que tendrá que ser llenado, "penetrado”, apropiado.

La torsión de Prado a los registros históricos se aprecia en el hecho de que efectivamente cuando Dutrou Bornier, el comerciante de la Polinesia, ocupa la isla, contrae matrimonio con Koreto, a quien nombra reina, como un modo de proclamar a Rapa Nui protectorado francés ${ }^{16}$. Este dato no aparece de manera explícita en las voces documentales primordiales que tuvo a mano, sin duda porque geopolíticamente no era conveniente resaltar este episodio, y quizás para no legitimar una asunción femenina del poder en la isla, así como por el hecho de que Koreto, luego del asesinato de Bornier a manos de los isleños, renovó la petición a Francia del protectorado. Prado, al representar el poder monárquico en una mujer, saca a luz el suceso histórico y con ello el doble y contradictorio gesto de romper con la genealogía de arikis hombres, pero al mismo tiempo que visibiliza el poder político femenino, lo elimina al hacer morir a Coemata Enú. Sin reina, la isla queda como suspendida en un hueco despojado de jerarquía y se convierte en una “isla oceánica”.

$16 \quad$ Es posible que Prado haya leído el artículo de Ricardo Beltrán y Rózpide, "La Isla de Pascua", del Boletín de la Sociedad de Geografía publicado en 1883, donde se relata la historia de la relación entre Koreto y Bornier. 
Este giro que hace el autor es visible en el propio título de la novela que se encarga de acentuar el protagonismo político femenino, unido a un gesto no menor: si en todos los documentos históricos se denomina Isla de Pascua -a pesar de consignar sus apelativos nativos-, él la nombra Rapa Nui. Al "bautizo católico" Prado opone el tahitiano con el que se autonombraron los propios isleños y con ello enlaza género y etnicidad como una fórmula para hablar de los “otros” exóticos y simultáneamente colocar una pregunta por sus diferencias.

Un segundo giro, relacionado con el anterior se produce en el modo en que se tematiza el conflicto y la violencia. En el capítulo "Un veterano de la guerra de Crimea” (que alude al dato histórico del pasado de Dutrou Bornier) y que es narrado desde la voz de Adams, las rivalidades internas entre los rapanui se habrían producido por un asunto "moral”. La llegada del francés a la isla, desliza el narrador, de acuerdo a "ciertos decires" que él no confirma, se habría motivado por:“... cierto robo de canacas para venderlos en el Perú a la Empresa de las Guaneras de las Islas Chinchas" (92).

En el primer viaje, Dutrou Bornier entra en conflicto con los "frailes" por sus vínculos con una mujer, y decide emprender una explotación de ganado, la que realiza con "poderes otorgados por las autoridades francesas". Pero, se da cuenta de que "los misioneros estaban entristeciendo a los alegres isleños" por la prohibición de la poligamia que predicaban los sacerdotes y observa que la propia reina se había refugiado, con sus partidarios, en otro sitio para huir de la catequización. El colonizador propone el plan de que sus súbditos lo tengan a él y a Adams como sacerdotes con más poder, de modo que “...de ahora en adelante solo nosotros podíamos hacer los verdaderos matrimonios y fijar las normas de conducta "(98). Así les "devuelve" la libertad (sexual) a los rapanui, pero desatando una "revolución" que tuvo como corolario que la mitad de los isleños abandonaran su tierra con los sacerdotes.

Más adelante, este suceso será leído como un nexo indisoluble entre amor y guerra, y en la imagen que construye un viejo sabio isleño: el amor en Rapa Nui es triste desde que el Rey Tepito (el padre de Coemata Enú) fue robado por un buque. Desde ese momento - no hay jefatura- todos se hacen la guerra entre sí, y los que escaparon de ese navío volvieron enfermos,

Y cundió el miedo y los hombres temían a las mujeres y las mujeres temían a los hombres, y como todos se deseaban, Rapa Nui se volvió loca de no poder amar sin caer en la muerte (123). 
Este mismo sabio se suicidará y en su funeral nuestro protagonista verá reflejada la unión muerte/amor y los grandes festejos en los cuales

[1]as cortesanas alternaban con las mujeres de vida un poco más recatada. Eran las primeras las codiciadas de los muchachos aunque aquellas prefiriesen la compañía de los hombres formados (132).

De este modo, Prado representa el conflicto colonial a partir de un Dutrou Bornier que si bien es dibujado como un posible esclavista, emerge como un "liberador" al desplazar el núcleo de los problemas de Rapa Nui a la evangelización que reprimía, particularmente, la libertad sexual de las mujeres. Por otro lado, desde el punto de vista del narrador, las consecuencias del tráfico de esclavos que afectó a los isleños se traducía en la imposibilidad de vivir la sexualidad debido a las enfermedades y la guerra interna. El problema entonces no era que la usurpación colonial vía el capitalismo, que representó históricamente Dutrou Bornier, haya producido una ruptura en el orden político y económico isleño, y que el esclavismo haya diezmado a gran parte de la población, sino que la liberalidad de que gozaban los "canacas" se vio amenazada por esta llegada de los "barcos" y de los "gabachos" (recordemos que los misioneros eran también franceses).

Prima en la Reina de Rapa Nui el estereotipo de la "tercera seducción" (Foerster 2010), en el sentido de la "economía trascendental del amor" polinésica, pero develando que desde la mirada del narrador chileno esa representación va de la mano con la instalación de la colonialidad de género. En la "lejana posesión” eros -cuya identidad es femenina- deberá preservarse para el goce masculino (claro que no cualquiera sino uno con nación: la chilena). Un goce que se asentará en la idea de que seguirá existiendo en ella lo insondable: “ $¡ O$ Oh! Misteriosa y tranquila Rapa Nui; envidio tu corte de impenetrables gigantes de piedra, porque su origen nadie penetrará jamás" (168), allí donde Coemata Enú “duerme entre sus súbditos ingenuos y desnudos” (loc. cit.). La tercera torsión impregna toda la novela y quizás es la que ha hecho posible que se haya reeditado hasta fines del siglo XX. Si en la documentación escrita e histórica sobre Rapa Nui los puntos de vista de viajeros, marinos y científicos -acorde con las concepciones expansionistas de la época-buscan describir a los "otros" nativos desde la noción evolucionista de "salvajes" y registrar -como en un gabinete de curiosidades semióticas- sus costumbres, así como analizar las posibilidades de explotación de sus recursos, en la novela de Pedro Prado estas dimensiones adoptan una nueva tesitura. Por un lado, tanto desde las voces narrativas del europeo como de los isleños hay una 
suerte de reflexividad que pretende universalizar y relativizar la oposición civilización/barbarie. Uno de los motivos donde esto se expresa es el del robo. Adams se queja ante la reina de que los isleños le sustraen ovejas, y ella le responde con una lógica impecable:

Me has dicho...que en tu país se castiga el robo. Y yo he comprendido que se castiga porque son muchos los que, no queriendo robar, no desean que otros se apoderen de sus cosas. En Rapa Nui, en cambio, todos roban a todos; de esta manera nadie hace daño a nadie. ¿Por qué no robas tú también? (71).

Los argumentos de Coemata Enú ofuscan al danés que califica a los isleños de mentirosos y ladrones. La reina sostiene que

[n]o nos comprendes y no te comprendemos...como todos sabemos que se nos quiere engañar, no creemos en lo que se nos dice...en tu lugar yo también mentiría; pero varios me han dicho que eres muy tonto para mentir (73).

La sabia reina invita al europeo a adoptar la cultura rapanui, pero al mismo tiempo refuerza las ideas que éste tiene de ellos (ladrones y mentirosos). Nuevamente Prado juega su viraje paradojal, pues denuncia y al mismo tiempo deja que los cimientos coloniales no se desplomen. Lo mismo sucede cuando el protagonista discute con Adams sobre el conflicto sexual que han ocasionado los misioneros y éste responde:

¡Ay; Señor; cuando uno ha dado la vuelta al mundo no ignora que hay muchas maneras de vivir, y no me venga a mí con que esta es buena y que la otra es mala. Ignorancia y nada más (96).

De este modo, bien y mal, así como eros y guerra, conviven permitiendo que el joven periodista no adopte un punto de vista sobre lo que ha conocido, relativizando de ese modo la violencia colonial. Si él se ha imbricado en la historia a través de su relación sexual y amorosa con la reina será solo para finalizar su relato borroneando todos los conflictos (las muertes, la amenaza de sequía, la monarquía acéfala, la explotación de Dutrou Bornier) y decirnos de Rapa Nui desde el barco de regreso:

Feminización y etnificación: "la reina de Rapa nui" de Pedro Prado "Feliz la vida de tus hijos, que viven lejos de la fiebre y de la ambición de los hombres nuevos. Feliz y sabia la existencia llevada entre 
fiestas de amor y de abundancia, y únicamente sujeta a las aguas del cielo (169).

Se podría concluir que esta tercera torsión construye la representación nacional de la "isla fantástica", pues no obstante los conflictos, la muerte, la violencia interna, la evangelización, los colonos, "los hijos viven felices” porque están distanciados del continente -sabemos que solo en el discurso cartográfico oficial-y únicamente se cierne sobre ellos la amenaza de la naturaleza. Sus "misterios" (la construcción de los moai por otros antes que ellos) quedan como impenetrabilidad, alegorizando el sentido femenino de la isla y desde ahí su abertura a una nueva “ocupación”.

\section{CONTEXTOS Y REEDICIONES}

Desde las tres torsiones de la novela, el vínculo problemático entre Chile y Rapa Nui se insinúa y esconde simultáneamente. La isla es admirable, entrañable, pero ¿quién la posee? Si leemos esta ficción histórica ahora considerando los contextos político-culturales en el que se producen sus sucesivas ediciones, la idea que sostuvimos de que la Reina de Rapa Nui opera como un dispositivo ligado a la colonialidad de género para definir en una red institucional y simbólica a los "otros" de la nación -en este caso a los rapanui- se hace más visible.

Un somero esbozo del devenir rapanui nos dice que las noticias y rumores que circulaban sobre Isla de Pascua a fines del siglo XIX y comienzos del XX eran "escandalosas" (Foerster 2010). Con la anexión de Rapa Nui en 1888 a través del Acuerdo de Voluntades, se inaugura un nuevo tinglado colonial. El Estado, representado por la Armada y sus autoridades, pacta en 1895 el arriendo de la isla a la Compañía Merlet, que desarrollará la hacienda ganadera, y posteriormente en 1903 a la Compañía Explotadora de Isla de Pascua, de propiedad de los anglo-escoceses Williamson and Balfour. Se oficializa así la producción de ovinos, pero junto a ella una figura empresarial y geopolítica que abre las tierras de la isla a los capitales extranjeros y, a la vez, las controla administrativamente, imponiendo las normativas del Estado, pero traspasando las funciones "civilizatorias" a esas firmas explotadoras. Mas, por la información que llegaba, el proyecto nacional de la Compañía no era tal, pues no había paz ni progreso sino explotación, miseria y degradación, así como resistencia y revueltas de los rapanui ante esa situación (Foerster 2014). 
Esta situación colonial permaneció sin cambios hasta la década de 1910, cuando el Estado intervino como respuesta a la rebelión de Angata (1914), por medio de monseñor Rafael Edwards. A través de la prensa de comienzos de siglo, las denuncias ${ }^{17}$ sobre las arbitrariedades cometidas evidencian la fisonomía especial que adquiere el colonialismo por el que optó Chile. Se trató de un pacto implícito entre la Compañía Exportadora de Isla de Pascua, la comunidad y el Estado, que les garantizaba a los rapanui el acceso a una economía parcelaria de subsistencia y de producción de maíz para el alimento del ganado.

La primera edición de la Reina de Rapa Nui, es de 1914 y realizada por la Imprenta Universitaria en un formato cuidado con tipografía art decó, sin ilustración en la portada, sino con un recuadro de viñetas. Cuando la novela comienza a circular en Rapa Nui se gesta la ya mencionada "Rebelión de Angata”. María Angata Veri Tahi a Pengo Hare Kohou sucedió al asesinado rey Riroroko; en impugnación a los malos tratos y a la negación de la comida por parte de la Compañía Explotadora, asumió un liderazgo particular. A través de un discurso religioso sincrético, calificado por algunos de milenarista, congregó a los isleños en pos de restituir el orden de las cosas arrasado por los colonizadores. La Rebelión de Angata, centrada en la gastropolítica, pone de manifiesto la resistencia de la comunidad y el papel de los sueños en las profecías de la anciana. La rebelión dio lugar a un cambio a través del “Temperamento de Voluntades” que comenzó a regular la vida en Rapa Nui. La novela ve la luz pública en este momento de conflicto, en medio de

17 Como aparece en las ediciones de El Chileno; La Unión, Lo Nuevo y el Libro de Julián Ruiz (todos de Valparaíso) por cuyos artículos conocemos los abusos sufridos por los rapanui bajo el mando del subdelegado marítimo empleado de la Compañía Merlet, Cooper. El testimonio de Manuel Vega (quien fue contratado como policía por Merlet y luego se opuso a sus arbitrariedades), casado con Verónica Mahute -viuda del rey Riro- bien pudo haber sido conocido por Prado, pues de algún modo Verónica representaba la "monarquía” y la unión entre una mujer rapanui y un chileno. Del mismo modo, entre las denuncias de Vega está el que Cooper obligaba a las mujeres a dejar a sus maridos para quedar a su servicio como concubinas (Foerster 2014). En El Chileno, se denuncia así el hecho: “Apenas tomó posesión de la ínsula (Cooper) organizó una cueca que dura todavía, y en la cual toman parte, de grado o por fuerza, todas las Venus de cara de hollín y de cabellera inaccesible al peine. No habiendo chicha, el aguardiente rebosa en el potrillo, y a falta de harpa, se sacan armonías con un tambor forrado de cuero en cuero de caballo y aporreado con el bastón del Gobernador" (Julio 1903). En una de las descripciones de Prado sobre las fiestas se habla del aguardiente con que se emborrachaban los isleños y, como ya vimos, el conflicto por las mujeres y su libertad sexual. 
una protesta indígena que puso de manifiesto desde esa época y hasta hoy que el "Acuerdo de Voluntades" fue comprendido de manera distinta por los rapanui y el Estado chileno.

La segunda edición (Nascimento 1938), se publicó ocho años después que Chile inscribiera las tierras de la isla a su nombre. Junto a ello se instaló de manera permanente el influjo de la Iglesia Católica (con los capuchinos) llevando a cabo un disciplinamiento evangelizador continuo, a la par que un proceso de "chilenización” cultural vía la escuela. Las tensiones y resistencias rapanui se mantuvieron realizando diversas demandas a la Compañía Explotadora. Por su lado, la "isla-Chile” vive un conjunto de transformaciones dadas por la asunción del Frente Popular al poder de la República y a una difusión de valores ligados al partido radical (laico), a las vertientes socialistas y demócratas. Es interesante señalar que la portada de esta segunda edición da cuenta de la estética imperante bajo ese nuevo modelo de compresión de la sociedad. Se aprecia en ella una política cultural de la imagen ligada al modernismo, con una base iconográfica soviética e influjos del muralismo mexicano ${ }^{18}$. Se observa en un primer plano a un hombre desnudo, semi oculto en una roca mirando a una mujer que emerge de las aguas. El imaginario colonial de género erótico y étnico queda plasmado en la imagen, haciendo un guiño a la primera torsión de la trama, de la que hemos hablado; sin embargo al exhibir la desnudez de ambos "liberaliza" la portada, en concordancia con los discursos progresistas y feministas que circulaban en la sociedad chilena ${ }^{19}$. Rapa Nui es simbolizado como un espacio donde la sexualidad heterosexual discurre a partir de la mirada del hombre que acecha (¿para penetrar?) a la bella mujer (¿alegoría de la isla?) como nacida de las aguas (una suerte de sirena) ${ }^{20}$.

18 Comunicación personal con Gloria Cortes (abril, 2015).

19 Recordemos que este es un momento de auge del feminismo que busca los derechos políticos y civiles de las mujeres.

20 Llama la atención que no es el "monumento" el que aparece sino los protagonistas, el occidental y la "reina", conjeturamos como representaciones figuradas del vínculo entre Chile (masculino) y Rapa Nui (femenino). 


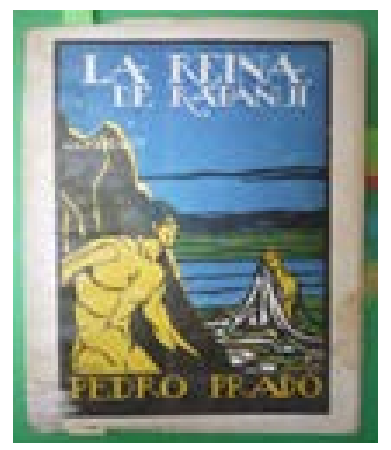

La tercera edición (Nascimento 1962) ocupa la misma portada anterior y solo se produce un cambio de color en los cuerpos, del rosado al amarillo. Han pasado 24 años desde que la editorial publicara la novela y diez de la muerte de su autor. ¿Qué ha sucedido en Rapa Nui? Nada menos que la obtención de la ciudadanía de sus habitantes. El año 1961, a raíz de la "Revolución de Sergio Rapu”, se logró la participación política (el derecho a voto) y las libertades civiles de los isleños. Del mismo modo, se inicia la conexión vía área con el continente y la llegada de funcionarios chilenos a la “lejana posesión”. Podríamos decir, que con todas esas transformaciones, en términos de la política colonial de la imagen, no varía la noción de la isla representada por las relaciones sexuales de género.

Tendrán que transcurrir 19 años para que se produzca la nueva edición de la novela. En 1983 y bajo plena la dictadura militar, la Editorial Andrés Bello en un convenio con la Televisión Nacional, edita nada menos que 30.000 ejemplares. Estamos frente a cambios radicales en su portada y en su factura:

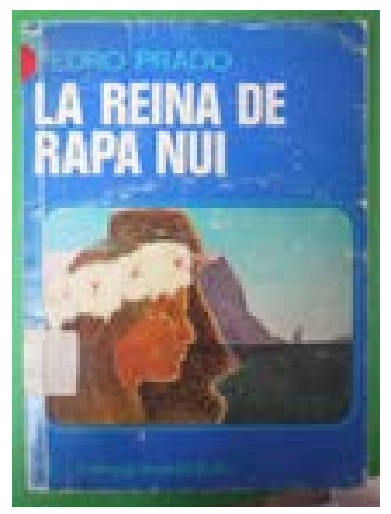


Se trata de una edición popular que contrasta con las otras, cuidadas y cosidas a mano ${ }^{21}$, con una caja considerable y una tipografía refinada y seguramente visadas por el autor. Ahora, similar a una promoción turística, aparece el perfil de una mujer polinésica en primer plano, tras el perfil del moai y las siluetas de los motu donde se practicaba la ceremonia del hombre pájaro. Ya no hay cuerpos desnudos, sino la representación de lo femenino folclorizado (el cintillo utilizado en los bailes polinésicos es el punctum del dibujo que como flecha delata la etnicidad); no hay cuerpos sino perfiles (el de la mujer, el del moai). Es el monumento y la lejana fascinación de la competencia por el huevo (el poder, el mana) lo que restalla. La mujer ya no se relaciona con un "otro" masculino de carne y hueso sino con su representación fálica, con la piedra que alegoriza el "misterio".

La década del 80 tuvo una gran relevancia económica para el mundo rapanui toda vez que Pinochet con una mirada estratégica hacia el Asia-Pacífico encontró el enclave geopolítico perfecto para asentar una participación de Chile en ese espacio, y asimismo por su "política indígena” que se basó en un populismo de subsidios y "reconocimiento a la cultura”. Sin duda, el propio papel de la Armada en la isla confabuló para que el dictador fuera visto de manera positiva por los rapanui. Pero, sobre todo, el énfasis en el mercado del turismo como elemento para el desarrollo fue impulsado a lo largo de las décadas militares.

La reaparición dentro de ese contexto, de La Reina de Rapa Nui, con una tirada completamente inusitada para el país, bajo una política cultural que declara en su contraportada estar al servicio de la lectura “...que es la gran alianza que inspira el convenio de cooperación entre estas dos corporaciones, a las que la ley ha asignado un papel preponderante en la conservación y el perfeccionamiento de los valores más auténticos de nuestra nacionalidad”, pone de manifiesto que la novela como dispositivo se acomoda, desde el punto de vista de los editores, a esos "valores nacionales" del neocolonialismo que comienza a imperar. De allí se puede desprender que el núcleo erótico desaparezca de la representación, para dar lugar a los nuevos íconos con que la nación comprenderá a Rapa Nui: un femenino detrás del cual está

21 De acuerdo a Gallardo e Ivo (2013), Pedro Prado ponía especial “...cuidado en el aspecto material de sus publicaciones: cada libro suyo fue siempre un pequeño objeto de arte. El papel, la tipografía, el diseño de la página, y muy especialmente la portada, fueron siempre cuidadosamente trabajados" (63). 
el peso del monumento y de la geografía (los motus), es decir aquello que se podrá "vender", circular, en la naciente industria turística que destaca la isla "remota", ya no la isla "esporádica", sino la antrópogena que obtiene identidad gracias a su autoaislamiento. La seducción que operaría sería la mezcla entre un eros aminorado y la piedra insondable.

Por último, en 1997 se reproduce una versión digital en la colección de libros electrónicos de la Facultad de Ciencias Sociales de la Universidad de Chile. Es una edición a cargo del lingüista Óscar Aguilera dentro de la colección Literatura Chilena.

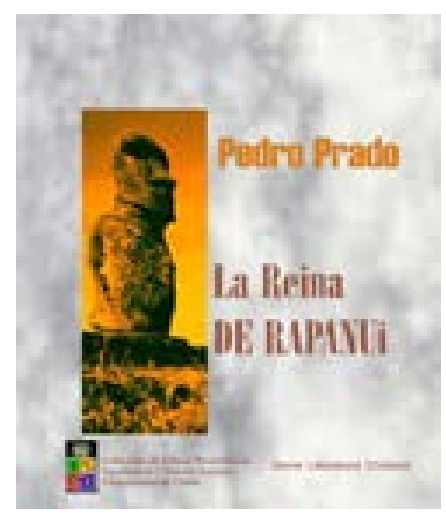

La década del 90 es sinónimo del retorno a la democracia, los sucesivos gobiernos de la Concertación de Partidos por la Democracia y sus políticas indígenas a través de la CONADI (creada en 1993) proveen un contexto donde la reproducción electrónica de La Reina de Rapa Nui devela por un lado, la modernización tecnológica del Chile globalizado económicamente, y por el otro, la reducción simbólica de la isla al monumento. Esta última portada de la novela despoja todo atisbo de sujetos femeninos o masculinos, para dar paso a una representación icónica fálica, ligada sin duda al turismo, a la seducción del misterio de su construcción y a la arqueología como decodificadora de la isla ${ }^{22}$. 


\section{COROLARIO}

Leída entonces La Reina de Rapa Nui como dispositivo colonial y de género, y haciendo un diálogo entre su contenido histórico-ficcional y su existencia material a través de las sucesivas ediciones, podemos percibir cómo la novela construye un discurso político-cultural que a lo largo del siglo XX trama la relación intrincada entre Chile y su "isla oceánica”. De novela romántica a denuncia y reproducción del colonialismo, pasa a configurar un imaginario de Rapa Nui donde su etnicidad es feminizada y erotizada, para luego irse desplazando desde ese núcleo a la circulación dineraria (la venta de su imagen turística). Los momentos históricos de su aparición y de sus reediciones ponen de manifiesto que la nación, de algún modo u otro, la ha elegido como representativa de sus concepciones del "otro" rapanui, es decir solidaria con la red de discursos y prácticas que construyen una mezcla de inquietud, de fascinación y de dominio sobre Isla de Pascua. Tal vez porque Pedro Prado captó esa profunda relación entre colonialismo, explotación y feminización de la isla (y de los isleños) que ha habido en los nexos entre rapanui y chilenos, es que la novela atraviesa el tiempo como dispositivo y que las políticas coloniales de la imagen den cuenta incluso del divorcio que a fines del siglo $\mathrm{XX}$ se aprecia entre democracia y mercado: eliminando los cuerpos solo queda el valor del monumento, de la ruina que permite el desarrollo. Por su lado, el argumento de la novela cubre y desnuda simultáneamente la génesis del complejo vínculo que el Estado y la sociedad civil chilena han construido con los rapanui, configurando un imaginario que opaca la historicidad del colonialismo chileno, así como la impugnación política isleña. Feminización e isla oceánica serán las tramas que hilan y rehilan los juegos de poder que subyacen a La Reina de Rapa Nui.

\section{BIBLIOGRAFÍA}

Agamben, G. “¿Qué es un dispositivo?” Sociológica 73 (2011): 249-264.

Bolaño, R. Los Detectives Salvajes. Anagrama, 1998.

Deleuze, G. (s.f.). Causas y razones de las islas desiertas: http://www.uaemex.mx/plin/colmena/ Colmena41/Aguijon/Gilles.html

Foerster, R. Rapa Nui y Chile: cuatro seducciones y sus lecturas. Mapocho 67 (2010): 51-73. El colonialismo republicano chileno cuestionado. Catalonia, 2014.

Foerster, R., S. Montecino, y C. Moreno. Documentos sobre Isla de Pascua (1864-1888).

Santiago de Chile: Biblioteca Fundamentos de la Construcción de Chile, 2013. 
Fuentes, M. Rapa Nui y la Compañía Explotadora. Rapa Nui: Rapanui Press, 2013.

Galilea, M. “La reina de Rapa Nui” de Pedro Prado (Una mirada desde la catástrofe). Espéculo, Revista de Estudios Literarios, 2010. Obtenido de http://pendientedemigracion.ucm.es/ info/especulo/numero45/rerapnu.html

Gallardo, A., y L. Ivo. Pedro Prado y Guilherme de Almeida. Academia Chilena de la Lengua/ Academia Brasileira de Letras, 2013.

Gotschlich, G. “Figura del novelista”. Licantropía n6-7 (dic.1996-mar.1997): 9-10.

Lugones, M. Colonialidad y género. Tabula Rasa 9, (2008): 73-101.

Mistral, G. (12 de Junio de 1932). Pedro Prado, escritor chileno. La Nación. Obtenido de http://www.gabrielamistral.uchile.cl/prosa/pprado.html

Montenegro, E. La Sonrisa de Pedro Prado. Revista Iberoamericana XVIII , 35 (1952): 93-104.

Prado, Pedro. La Reina de Rapa Nui, Imprenta Universitaria, Santiago, 1914, Primera Edición; Nascimento, Santiago, 1938, Segunda Edición; Nascimento, Santiago, 1962 Tercera Edición; Editorial Andrés Bello, Santiago, 1983, Cuarta Edición y Colección de Libros Electrónicos, Facso, Universidad de Chile, Santiago, 1997.

Silva Castro, R. Pedro Prado 1886-1952. Santiago: Andrés Bello, 1965.

Sloterdijk, P. Esferas III. Siruela, 2009. 